\title{
IL-10 and TNF- $\alpha$ polymorphisms in subjects with irritable bowel syndrome in Mexico
}

\author{
Max Schmulson ${ }^{1}$, Daniela Pulido-London ${ }^{1}$, Óscar Rodríguez ${ }^{1}$, Norma Morales-Rochlin ${ }^{1}$, Rosalinda \\ Martínez-García ${ }^{1}$, María Concepción Gutiérrez-Ruiz², Juan Carlos López-Alvarenga ${ }^{3}$ and Gabriela \\ Gutiérrez-Reyes ${ }^{1}$
}

${ }^{1}$ Laboratory of Liver, Pancreas and Motility (HIPAM). Department of Experimental Medicine. School of Medicine. Universidad Nacional Autónoma de México (UNAM). Hospital General de México. México. ${ }^{2}$ Universidad Autónoma Metropolitana (UAM)-Iztapalapa. México. ${ }^{3}$ Center of Biostatistics. Department of Clinical Investigation. Hospital General de México. México

\begin{abstract}
Background: there has been recent evidence of an alteration in irritable bowel syndrome (IBS) immune regulation, as well as variations in cytokine polymorphisms.

Aims: to determine the frequency of the IL-10 $(-1082 \mathrm{G} / \mathrm{A})$ and TNF- $\alpha$ (-308G/A) polymorphisms in subjects with IBS in Mexico.

Methods: volunteers answered the Rome II Questionnaire and were classified as IBS $(n=45)$ and controls $(n=92)$. The IBS subjects were then categorized as IBS-D: $22.2 \%$, IBS-C: $28.9 \%$, and IBS-A/M: $48.9 \%$. The polymorphism frequency among groups was compared.

Results: there were no differences between IBS vs. controls in the frequency of the high (8.9 vs. $18.5 \%$ ), intermediate (60.0 vs. $57.6 \%$ ), or low (23.9 vs. $38.9 \%)$ producer IL-10 genotypes, $\mathrm{p}$ $=0.315$. Neither were there differences in the high (0 vs. $1.1 \%)$, intermediate (55.4 vs. $43.2 \%$ ), or low (43.5 vs. $56.8 \%$ ) producer TNF- $\alpha$ genotypes, $p=0.296$. However the low producer of IL-10 was more frequent in IBS-D vs. IBS-C vs. IBS-A/M (63.6 vs. 7.1 vs. $33,3 \%) \mathrm{p}=0.023$.

Conclusions: in this group of volunteers in Mexico, the frequency of the IL-10 (-1082G/A) and TNF- $\alpha$ (-308G/A) genotypes was similar in IBS and controls. However, there was a greater frequency of the low producer of IL-10 in those subjects with IBS-D, suggesting a genetic predisposition to abnormal immune regulation due to a lower anti-inflammatory component in this subgroup.
\end{abstract}

Conflict of interest: In the last 2 years, Max Schmulson has received research funding from Nestlé Ltd. and Nycomed/Takeda México. He has been a member of the Advisory Council of Alfa Wasserman, an advisor for Almirall, Janssen and Nestlé Ltd., and a speaker for Alfa Wasserman, Janssen, and Takeda México. Juan Carlos López-Alvarenga has acted as a biometrics analyst for Takeda México. The remaining authors have nothing to declare. Declarations: Dr. Max Schmulson presented this study upon his induction into the Academia Nacional de Medicina de México in 2012.

Received: 05-03-2013

Accepted: $19-08-2013$

Correspondence: Max Schmulson. Laboratory of Liver, Pancreas and Motility (HIPAM). Department of Experimental Medicine. School of Medicine. Universidad Nacional Autónoma de México (UNAM). Hospital General de México. Dr. Balmis \#148. Col. Doctores. C.P. 06726 México D.F. México. e-mail: maxjulio@prodigy.net.mx
Key words: Irritable bowel syndrome. Genotypes. Interleukins. IL-10. TNF- $\alpha$. Diarrhea. Constipation. Immunoregulation. Mexico.

\section{INTRODUCTION}

The pathophysiology of irritable bowel syndrome (IBS) is not fully understood. Several mechanisms have been proposed, such as altered intestinal motility, visceral sensitivity, alterations in the two-way communication between the brain and gut, stress, and psychological factors (1-3). More recently, a group of patients developing IBS after a gastrointestinal infection, known as Post-Infectious IBS (PI-IBS) (4) has been described, but differences have also been demonstrated in the microbiota in adults and children with IBS when compared with controls $(5,6)$. On the other hand, the presence of low-grade inflammation in the colon mucosa has been reported in a subgroup of patients with IBS, consisting of an increase in the number of intraepithelial lymphocytes, mast cells, and/or enterochromaffin cells $(7,8)$. Moreover, this low grade inflammation appears to be primarily related to PI-IBS (9).

Other immune regulation alterations that have been reported in IBS include lower levels of serum interleukin-10 (IL-10) and higher levels of pro-inflammatory cytokines such as the tumor necrosis factor alpha (TNF- $\alpha$ ) (10). In Mexico, for example, we have very recently reported that the presence of lower levels of serum IL-10,

Schmulson M, Pulido-London D, Rodríguez O, Morales-Rochlin $N$, Martínez-García R, Gutiérrez-Ruiz MC, López-Alvarenga JC, Gutiérrez-Reyes G. IL-10 and TNF- $\alpha$ polymorphisms in subjects with irritable bowel syndrome in Mexico. Rev Esp Enferm Dig 2013;105:392-399. 
in volunteers with IBS according to the Rome II diagnostic criteria (10), is a predictive factor for this disorder, especially in women that have diarrhea-predominant IBS (IBS-D). We also found higher serum TNF- $\alpha$ levels in subjects with IBS, when compared with controls.10 Likewise, recent data have described an association between IBS and genes related to the immune response (11-13). Accordingly, cytokines are the ideal candidates for genetic studies on IBS, given that their expression is genetically regulated (14). The predisposition to produce high or low levels of a specific cytokine could be related to the presence of the polymorphisms that encode each of their gene expressions, as has been suggested for the immunoregulatory IL-10 and the pro-inflammatory TNF- $\alpha$ cytokines $(15,16)$. These polymorphisms could then affect the susceptibility for developing IBS, as well as its phenotypic expressions (IBS-D; constipation-predominant IBS: IBS-C; and alternating/mixed IBS: IBS-A/M), at least in a subgroup of patients in whom immune activation would be a supposed factor. Nevertheless, according to a recent systematic review of the literature, the data on the genetic variants of the cytokines in IBS and controls are inconsistent (17). On the other hand, no studies on polymorphisms in IBS have been conducted in Latin America to date (18).

Therefore, our aim was to explore the frequency of the IL-10 polymorphisms in a group of volunteers in Mexico City, divided into subjects with IBS and controls. Our hypothesis was that the subjects with IBS, when compared with the controls, should present with a greater frequency of both the low producer IL-10 polymorphism and the high producer TNF- $\alpha$ polymorphism.

\section{METHODS}

\section{Subjects}

The present study was conducted on volunteers from a university in southeast Mexico City (Universidad Autónoma Metropolitana: UAM-Iztapalapa) that participated in an epidemiologic and serologic study on functional gastrointestinal disorders (FGIDs) (19). The volunteers were recruited through advertisement by posters put up in different areas of the university. The only inclusion criterion for the epidemiologic study was age. The participants had to be over 18 years old and they included students, teachers, and administrative and general service personnel. No analyses were done to exclude celiac disease or lactose intolerance, inflammatory bowel disease or microscopic colitis, or a history of gastrointestinal infection or any other factor that could trigger IBS. Whether the participants were under any drug treatment, including medication that could affect motility, anti-inflammatory agents, or steroids was not determined either. The study focused exclusively on determining FGID frequency.

\section{The Rome II Modular Questionnaire in Spanish in Mexico}

All the subjects answered the Rome II Modular Questionnaire that had previously been translated into Spanish, as well as validated, in Mexico (19). The subjects that fit the criteria for IBS and the FGID-negative controls were invited to participate in the present study on the IL-10 and TNF- $\alpha$ polymorphisms. In accordance with the predominant bowel habit, the IBS subjects were then divided into the IBS-D and IBS-C subtypes; those subjects that did not fit the IBS-D or IBS-C criteria were regarded as IBS-A/M.

\section{Polymorphism determination}

A venous blood sample was collected from the subjects that had signed informed consent statements to participate in the study. Leukocyte DNA was extracted through the salting out technique using the BDTract ${ }^{\mathrm{TM}}$ Genomic DNA Isolation Kit (Maxim Biotech Inc). Cytokine genotyping was done through the amplification-refractory mutation system (ARMS). The polymorphisms of the IL-10 promoter regions at positions $-1082 * \mathrm{G}$ and $-1082 * \mathrm{~A}$ and the TNF- $\alpha$ promoter regions at positions $-308^{*} \mathrm{G}$ and $-308^{*} \mathrm{~A}$ were analyzed through the polymerase chain reaction (PCR) using specific oligonucleotides for identifying the high and low producer alleles from each bi-allelic polymorphic site. The amplified DNA products were separated through electrophoresis in $2 \%$ agarose gel and stained with ethidium bromide. The gel was visualized under ultraviolet (UV) transillumination with a marker that had a molecular weight of 100 base pairs (bp), and they were photographed. The genotypes were expressed as high or low producers for the homozygotes and as intermediate producers for the heterozygotes (20). It should be mentioned that the genotyping was blinded; there was no knowledge of the clinical characteristics of the subjects; in other words, it was not known whether they presented with IBS or were controls.

The study protocol was approved by the Research Committee of the Faculty of Medicine of the Universidad Nacional Autónoma de México (UNAM). All subjects signed informed consent statements.

\section{Statistical analysis}

The continuous variables were expressed as means and the categorical variables as percentages and $95 \%$ CI. The genotype distribution between the cases and controls was compared using the Pearson's chi-square test and the http:// ihg.gsf.de/cgi-bin/hw/hwa1.pl website was used to determine the Hardy-Weinberg equilibrium for the cases and controls.

This study was an exploratory one, so the sample size was not determined a priori, given that the frequency of 
the alleles and the genotypes studied was not known for the Mexican or Latin American population. On the other hand, the prevalence of alleles in a population is a variable of which its mathematical expectation has to be calculated as a random type one. In the present study this variable was used to classify the subject groups, resulting in a pseudo-experimental analysis. Because the difference between alleles for a particular phenotype varies, the post hoc statistical power will also vary in relation to the phenotypic differences found. Based on the above, the values for a two-tailed $\mathrm{Z}$ test for obtaining proportional differences are consistent with the following statistical power values: Differences of $0.15,0.20,0.25$, and 0.30 correspond to a post hoc statistical power of $60,83,95$, and $99 \%$, respectively. Taking into account differences in phenotypic frequencies greater than $20 \%$ between the subjects with IBS and the controls in our study (for example: The frequency of abdominal pain or discomfort or bowel habit characteristics), the post hoc statistical power was above $83 \%$.

\section{RESULTS}

One hundred and thirty-seven volunteers participated in the study. Of that total, 45 fit the IBS criteria and 92 were regarded as controls. Table I shows the epidemiologic and clinical characteristics of the groups. There were no statistically significant differences in age, sex, and body mass index (BMI) between the IBS subjects and the controls. Further, the subjects with IBS were classified as IBS-D: $22.2 \%$, IBS-C: $28.9 \%$, and IBS-A/M: $48.9 \%$ and no differences in age, sex distribution, or BMI were found among these IBS subgroups. On the other hand, in relation to the intestinal symptoms evaluated in the Rome II Modular Questionnaire, abdominal pain and discomfort were more frequent in the subjects with IBS, compared with the controls, as was to be expected. Likewise, the presence of loose stools, straining, the sensation of incomplete evacuation, mucus in the stools, and the sensation of abdominal fullness, inflammation, or swelling were more frequent in the subjects with IBS. In relation to the IBS subtypes, there was no difference in the frequency of abdominal pain or discomfort, but those subjects with IBS-D had a greater frequency of more than 3 defecations per day, loose or watery stools, and defecation urgency, whereas those with IBS-C had a greater frequency of hard stools and straining (Table I).

The frequency of the IL-10 (-1082G/A) genotypes was in the Hardy-Weinberg equilibrium for both the cases and the controls (Table II); however, the frequency of the TNF- $\alpha$ (-308G/A) genotypes was in significant departure (Table III).

The intermediate producer IL-10 polymorphism was the predominant one in the majority of the subjects with IBS and the controls, followed by the low producer and no differences were found in the frequency of the geno- types or alleles (Table II). In regard to TNF- $\alpha$, practically no high producer genotype was found in the entire study population, with the exception of one control subject. No differences were found between the IBS subjects and the controls, either (Table III).

Statistically significant differences were found upon comparing the frequency of the IL-10 genotypes among the IBS-D vs. IBS-C vs. IBS A/M subgroups. The low producer genotype was predominant in IBS-D, whereas the intermediate producer genotype was predominant in IBS-C and IBS-A/M, ( $=0.023$ ) (Fig. 1). In contrast, no differences in the frequency of the TNF- $\alpha$ genotypes were found among the IBS subgroups $(p=0.146)$. None of the subjects with IBS presented with the high producer TNF- $\alpha$ genotype (Fig. 1).

\section{DISCUSSION}

In the present study on volunteers in Mexico, we found no differences in the frequency of the genotypes or the alleles of the IL-10 (-1082G/A) and the TNF- $\alpha$ (-308G/A) polymorphisms in the comparison between the subjects that fit the Rome II criteria for IBS and the controls that did not fit the criteria for this gastrointestinal functional disorder. In addition, the high producer TNF- $\alpha$ (AA) polymorphism was found to be practically absent in this population. In the polymorphism analysis of the IBS subgroups, the low producer of IL-10 (AA) was significantly more frequent in those subjects with IBS-D, whereas the intermediate producer was significantly more frequent in the subjects with IBS-C. There were no differences in the TNF- $\alpha$ genotypes among the IBS subgroups in our volunteer population.

Due to the fact that cytokine production is genetically determined, their respective polymorphisms may be different in subjects with IBS and in controls without the criteria for this disorder (14), but results with respect to this have not been conclusive. A previous study conducted in Turkey reported a lower frequency of the high producer IL-10 genotype in position -1082 in patients with IBS, when compared with controls (15). These findings suggest a genetic predisposition to an immune regulation alteration in subjects with IBS. In contrast, no differences were found in these polymorphisms between IBS and controls in studies in Holland (16), South Korea (21), China (22), and India (23).

On the other hand, in Holland, the intermediate producer TNF- $\alpha$ polymorphism in position -308 was more frequent in IBS (16), whereas no differences in the TNF- $\alpha$ polymorphisms were found in IBS $v s$. controls in the South Korean (21) and Indian (23) studies.

In our study on volunteers in Mexico City, we observed no differences in the prevalence of the IL-10 (-1082G/A) and TNF- $\alpha$ (-308G/A) genotypes between IBS and controls, similar to that reported in previous Asian studies. 
Table I. General characteristics of the study groups

\begin{tabular}{|c|c|c|c|c|c|c|c|}
\hline & $\begin{array}{l}\text { Controls } \\
(n=92)\end{array}$ & $\begin{array}{l}\text { IBS } \\
(n=45)\end{array}$ & $p$ & $\begin{array}{l}I B S-D \\
(n=10)\end{array}$ & $\begin{array}{l}\text { IBS-C } \\
(n=13)\end{array}$ & $\begin{array}{l}I B S-A / M \\
(n=22)\end{array}$ & $p$ \\
\hline Sex: Female, n (\%) & $56(68.3)$ & $34(69.4)$ & 0.207 & $8(80)$ & $8(61.5)$ & $14(63.6)$ & 0.593 \\
\hline $\begin{array}{l}\text { Age: Years, mean } \\
(95 \% \mathrm{Cl})\end{array}$ & $33.8(31.1 ; 36.4)$ & $31.2(27.7 ; 34.7)$ & 0.251 & $25.8(21.3 ; 30.3)$ & $29.5(24.1 ; 34.8)$ & $34.8(28.7 ; 41.0)$ & 0.134 \\
\hline BMI: Mean (95 \% CI) & $24.4(24.8 ; 26.4)$ & $25.7(23.4 ; 25.4)$ & 0.076 & $26.2(23.6 ; 28.7)$ & $23.0(21.6 ; 24.5)$ & $24.6(23.2 ; 26.0)$ & 0.114 \\
\hline $\begin{array}{l}\text { BMI: Categories \% } \\
(95 \% \text { Cl) }\end{array}$ & & & 0.620 & & & & 0.816 \\
\hline Underweight & $2.2(0.26 ; 7.6)$ & 0 & & 0 & 0 & 0 & \\
\hline Normal & $47.8(37.3 ; 58.5)$ & $61.0(44.3 ; 74.3)$ & & $55.6(21.2 ; 86.3)$ & $72.7(39.0 ; 94.0)$ & $57.1(34.0 ; 78.2)$ & \\
\hline Overweight & $35.6(26.1 ; 46.5)$ & $31.7(18.2 ; 46.6)$ & & $33.3(7.4 ; 70.1)$ & $27.3(6.0 ; 61.0)$ & $33.4(14.5 ; 57.0)$ & \\
\hline Obesity & $14.4(7.7 ; 22.9)$ & $7.3(1.4 ; 18.2)$ & & $11.1(0.3 ; 48.2)$ & 0 & $9.5(1.2 ; 30.4)$ & \\
\hline \multicolumn{8}{|l|}{$\begin{array}{l}\text { Clinical characteristi } \\
\text { according to the } \\
\text { Rome II Modular } \\
\text { Questionnaire: \% } \\
\text { (95\% Cl) }\end{array}$} \\
\hline $\begin{array}{l}\text { Abdominal pain or } \\
\text { discomfort in the last } 3 \\
\text { months }\end{array}$ & $28.3(19.4 ; 38.6)$ & $93.3(31.7 ; 98.6)$ & $<0.001$ & 100 (69.0; 100) & $84.6(54.5 ; 98.1)$ & $95.5(77.2 ; 99.9)$ & 0.292 \\
\hline $\begin{array}{l}\text { The pain or discomfort } \\
\text { improves or disappears } \\
\text { after a bowel } \\
\text { movement }\end{array}$ & $12.8(6.6 ; 21.7)$ & $65.9(50.1 ; 79.5)$ & $<0.001$ & $50.0(18.7 ; 81.3)$ & $83.3(51.5 ; 97.9)$ & $63.6(40.7 ; 82.8)$ & 0.247 \\
\hline $\begin{array}{l}\text { When the abdominal } \\
\text { pain or discomfort } \\
\text { begins, there is a } \\
\text { change in the frequency } \\
\text { of bowel movements }\end{array}$ & 0 & $63.6(47.8 ; 77.6)$ & $<0.001$ & $70.0(34.7 ; 93.3)$ & $50.0(21.1 ; 78.9)$ & $68.2(45.1 ; 86.4)$ & 0.513 \\
\hline $\begin{array}{l}\text { When the abdominal } \\
\text { pain or discomfort } \\
\text { begins, there is a } \\
\text { change in stool } \\
\text { consistency (looser or } \\
\text { harder than normal) }\end{array}$ & $2.3(0.3 ; 8.1)$ & $79.5(64.7 ; 90.2)$ & $<0.001$ & $90.0(55.5 ; 99.7)$ & $91.7(61.5 ; 99.8)$ & $68.2(45.1 ; 86.1)$ & 0.174 \\
\hline $\begin{array}{l}\text { Fewer than } 3 \text { bowel } \\
\text { movements per week }\end{array}$ & $12.0(0.7 ; 19.0)$ & $15.6(6.5 ; 29.5)$ & 0.558 & $40.0(12.2 ; 73.8)$ & $7.7(2.0 ; 36.0)$ & $9.1(1.1 ; 29.2)$ & 0.053 \\
\hline $\begin{array}{l}\text { More than } 3 \text { bowel } \\
\text { movements per day }\end{array}$ & $21.7(13.8 ; 31.6)$ & $37.8(23.8 ; 53.5)$ & 0.047 & $90.0(55.5 ; 99.7)$ & 0 & $36.8(17.2 ; 59.3)$ & $<0.001$ \\
\hline Hard or lumpy stools & $17.4(10.3 ; 26.7)$ & $48.9(33.7 ; 64.2)$ & $<0.001$ & 0 & $92.3(63.9 ; 99.8)$ & $45.5(24.2 ; 67.8)$ & $<0.001$ \\
\hline $\begin{array}{l}\text { Loose, mushy, or watery } \\
\text { stools }\end{array}$ & $23.9(15.6 ; 33.9)$ & $46.7(31.7 ; 62.1)$ & 0.007 & $\begin{array}{l}100.0(74.1 ; \\
100)\end{array}$ & $15.4(1.9 ; 45.4)$ & $40.9(22.1 ; 62.0)$ & $<0.001$ \\
\hline $\begin{array}{l}\text { Straining during a } \\
\text { bowel movement }\end{array}$ & $3.3(0.7 ; 9.2)$ & $28.9(16.3 ; 44.3)$ & $<0.001$ & 0 & $61.5(31.6 ; 86.1)$ & $22.7(7.8 ; 45.3)$ & 0.004 \\
\hline Defecation urgency & $34.8(25.1 ; 45.4)$ & $51.1(35.8 ; 66.3)$ & 0.067 & $80.0(44.4 ; 97.5)$ & $23.1(5.0 ; 53.8)$ & $54.5(32.2 ; 75.6)$ & 0.023 \\
\hline $\begin{array}{l}\text { Sensation of incomplete } \\
\text { evacuation }\end{array}$ & $8.7(3.8 ; 16.4)$ & $22.2(11.2 ; 37.1)$ & 0.028 & $30.0(6.7 ; 65.2)$ & $15.4(1.9 ; 45.4)$ & $22.7(7.8 ; 45.4)$ & 0.703 \\
\hline Mucus in stools & $29.3(20.3 ; 39.8)$ & $77.8(62.9 ; 88.8)$ & $<0.001$ & $90.0(0.55 ; 99.7)$ & $69.2(38.6 ; 90.9)$ & $77.3(54.6 ; 92.2)$ & 0.492 \\
\hline $\begin{array}{l}\text { Sensation of abdominal } \\
\text { fullness, inflammation, } \\
\text { or swelling }\end{array}$ & $26.1(17.5 ; 36.3)$ & $46.7(31.7 ; 62.1)$ & 0.016 & $90.0(55.5 ; 99.7)$ & $15.4(1.9 ; 45.4)$ & $45.5(24.4 ; 67.8)$ & 0.002 \\
\hline
\end{tabular}


Table II. Distribution of the IL-10 genotypes and alleles in IBS and controls

\begin{tabular}{|c|c|c|c|c|c|c|c|}
\hline \multirow[t]{4}{*}{ Groups } & \multirow[t]{3}{*}{ All } & \multicolumn{3}{|c|}{ Genotype frequency } & \multicolumn{2}{|c|}{ Allele frequency } & \multirow[t]{3}{*}{ HWE } \\
\hline & & High producer & $\begin{array}{l}\text { Intermediate } \\
\text { producer }\end{array}$ & Low producer & High producer & Low producer & \\
\hline & & $G G$ & $G A$ & $A A$ & G & $A$ & \\
\hline & $n$ & \multicolumn{3}{|c|}{$n(\%)$} & \multicolumn{2}{|c|}{$n(\%)$} & $p^{*}$ \\
\hline IBS & 45 & $4(8.9)$ & $27(60.0)$ & $14(31.1)$ & 35 (38.9) & $55(61.1)$ & 0.120 \\
\hline Controls & 92 & $17(18.5)$ & $53(57.6)$ & $22(23.9)$ & $87(47.3)$ & $97(52.7)$ & 0.208 \\
\hline $\mathrm{p}$ & & \multicolumn{3}{|c|}{0.315} & \multicolumn{2}{|c|}{0.189} & \\
\hline
\end{tabular}

HWE: Hardy-Weinberg equilibrium. *Data analyzed through the exact p-value with maximum reliability.

Table III. Distribution of the TNF- $\alpha$ genotypes and alleles in IBS and controls

\begin{tabular}{|c|c|c|c|c|c|c|c|}
\hline \multirow[t]{4}{*}{ Groups } & \multirow[t]{3}{*}{ All } & \multicolumn{3}{|c|}{ Genotype frequency } & \multicolumn{2}{|c|}{ Allele frequency } & \multirow[t]{4}{*}{ HWE } \\
\hline & & High producer & $\begin{array}{l}\text { Intermediate } \\
\text { producer }\end{array}$ & Low producer & High producer & Low producer & \\
\hline & & $A A$ & $G A$ & GG & $A$ & G & \\
\hline & $n$ & \multicolumn{3}{|c|}{$n(\%)$} & \multicolumn{2}{|c|}{$n(\%)$} & \\
\hline IBS & 44 & 0 & $19(43.2)$ & $25(56.8)$ & $19(21.6)$ & $69(78.4)$ & $<0.001$ \\
\hline Controls & 92 & $1(1.1)$ & $51(55.4)$ & $40(43.5)$ & $53(28.8)$ & $131(71.2)$ & $<0.001$ \\
\hline$p$ & & \multicolumn{3}{|c|}{0.296} & \multicolumn{2}{|c|}{0.207} & \\
\hline
\end{tabular}

HWE: Hardy-Weinberg Equilibrium. *Data analyzed through the exact p-value with maximum reliability.

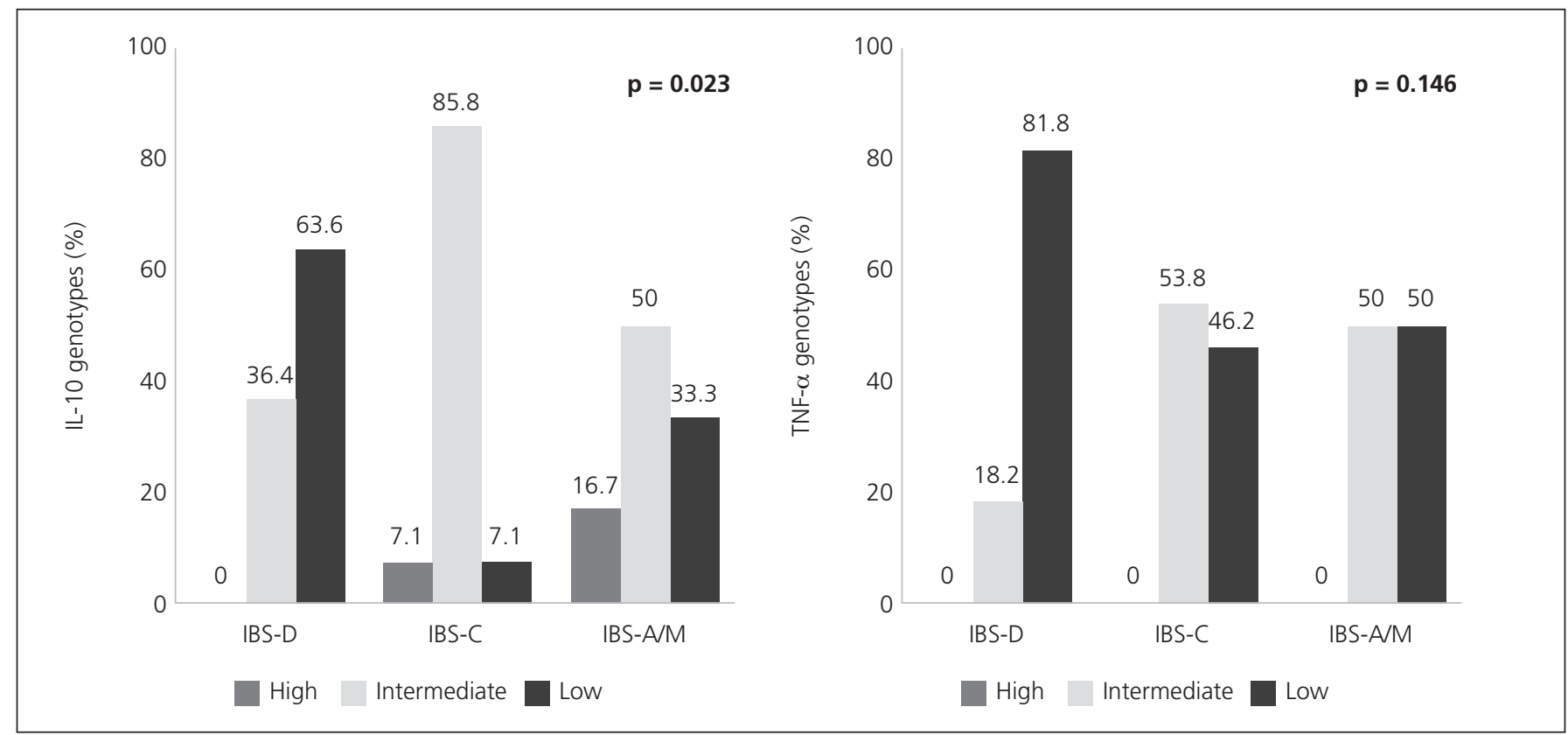

Fig. 1. The figure shows the frequency of the IL-10 (-1082G/A) and TNF- $\alpha(-308 G / A)$ genotypes according to the IBS subgroups. One can see on the left that the low producer of IL-10 (A/A) predominated in IBS-D, whereas the intermediate producer genotype (G/A) was predominant in IBS-C and IBSA/M. The TNF- $\alpha$ genotype distribution is shown on the right, and there were no differences between the groups. It should be noted that none of the IBS subjects presented with the high producer genotype (A/A). 
This lack of differences could be due to the population variations, themselves, or to the fact that our sample size did not enable a definite conclusion to be reached. However, with respect to the latter, we believe that our study sample was representative of the university population analyzed because the $34.7 \%$ frequency of IBS was similar to the $35.5 \%$ previously found in that community (19). Despite the fact that no differences were found in the polymorphisms studied between the subjects with IBS and the controls, interestingly we did observe significant differences in IBS-D when compared with the other IBS subgroups; and there was a greater frequency in the low producer IL-10 polymorphism in that subgroup. These findings, which are suggestive of a genetic predisposition to an abnormal immune regulation in subjects with IBS-D, concur with other data in the literature. For example, recently in the same population in Mexico, we found that the presence of low serum levels of IL-10 was an independent predictive factor for IBS (10). Furthermore, women with IBS-D presented with lower IL-10 levels compared with those with IBS-C and IBS-A/M. Other data in the literature also suggest immune regulation alterations, especially in IBS-D. For example, higher IL-10 levels derived from mononuclear cells from peripheral blood in IBS-D, when compared with controls, have been reported, even though no differences were reported in the comparison with the IBS-C or IBS-A/M subgroups (24). Other factors have also been found, such as an increase in the serine proteases in stools in IBS-D, when compared with IBS-C and IBS-A/M (25). These proteases can trigger an increase in cellular permeability, which has also been found to be associated with an increase in defecation frequency (26), as well as with IBS-D itself (27). Even though our findings are compatible with a genetic predisposition to produce lower levels of the anti-inflammatory IL-10 cytokine in subjects with IBS-D, the design of our study did not allow for us to determine whether the greater frequency of the low producer IL-10 genotype would result in lower levels of this serum cytokine, lower expression in the colon mucosa, or in a predisposition to low grade inflammation in the colon mucosa, as has been described in patients with IBS. In the first study conducted in the United States regarding this, Chang et al. evaluated both serum cytokines and their level of expression in the colon mucosa, finding only a lower expression of IL-10 mRNA in the mucosa, with no differences in its cellularity or in the serum levels of the cytokines (28). Given the above, the relation of the abnormalities in the immune regulation alterations due to the serum cytokines and the low grade inflammation in the colon mucosa are still to be determined (8).

Regarding the TNF- $\alpha$ (-308G/A) polymorphism, more than half of the subjects of our population presented with the intermediate producer genotype, which is a greater frequency than that found in Caucasians and Asians $(16,18,29)$. In contrast, we found a very low frequency of the high producer TNF- $\alpha$ polymorphism in both the IBS subjects and the controls and we found no differences in the frequency of the A and $G$ alleles, similar to that reported by Barkhordari in Iran (29). The low frequency of the high producer of TNF- $\alpha(-308 \mathrm{~A})$ has also been described in general population studies (30). In addition, the presence of the high producer allele in position -308A has been related to a greater production of TNF- $\alpha$ induced by bacterial lipopolysaccharides (LPS) in peripheral mononuclear cells of subjects with inflammatory bowel disease (31), and appears to be related to a lower response to treatment with anti-TNF agents in rheumatologic diseases (32). Nevertheless, unlike the previously mentioned diseases, IBS is not a true inflammatory disease, which probably explains the low frequency that we found in the high producer in both IBS and the controls. Finally, we should mention the deviation from the Hardy-Weinberg equilibrium found for the TNF- $\alpha$ genotypes in our volunteers with IBS and in the controls. This finding may be related to the genetic crossing that occurs in mestizo populations, which are the majority in Mexico $(33,34)$.

Our study has certain limitations. First of all, the small sample size may be the reason why no differences were found in the IL-10 and TNF- $\alpha$ polymorphisms between IBS subjects and the controls. This, however, was not a restriction for the differences observed between the IBS subgroups that were even lower. In addition we obtained a good post hoc statistical power. At any rate, large population studies in Mexico are needed to confirm our findings. Secondly, we did not determine any differences between subjects with PI-IBS and those without a history of gastrointestinal infections as a triggering factor for IBS. However, it should be noted that PI-IBS frequency is very low in Mexico (35). We also did not rule out the presence of celiac disease or inflammatory bowel disease in these subjects, which could have modified the frequency of the polymorphisms studied. But our study has the strength of having been conducted on community subjects as opposed to patients, and of being the first genetic study in IBS in a Latin American population. Finally, we did not correlate our findings on the polymorphisms with the serum levels of their respective cytokines or with their expression in the colon mucosa and thus did not determine the role the study polymorphisms have in relation to these cytokines and the immune regulation at the level of the colon, the target organ in IBS.

In conclusion, in this group of volunteers in Mexico, no differences were found in the frequency of the IL-10 (-1082G/A) and TNF- $\alpha$ (-308G/A) genotypes. However, the subjects with IBS-D presented with a greater frequency of the low producer IL-10 genotype, suggesting a genetic predisposition to an abnormal immune regulation due to a lower anti-inflammatory component in this subgroup. Large-scale population studies are needed to confirm our findings. 


\section{ACKNOWLEDGMENTS}

The study was financed by the research fund PAPIIT, IN-211107 of the DGAPA, UNAM. Óscar Rodríguez-Fandiño received grant No. 336205 from the Consejo Nacional de Ciencia y Tecnología (CONACyT) de México.

\section{REFERENCES}

1. Hasler WL. Traditional thoughts on the pathophysiology of irritable bowel syndrome. Gastroenterol Clin North Am 2011;40:21-43.

2. Surdea-Blaga T, Baban A, Dumitrascu DL. Psychosocial determinants of irritable bowel syndrome. World J Gastroenterol 2012;18:616-26.

3. Konturek PC, Brzozowski T, Konturek SJ. Stress and the gut: pathophysiology, clinical consequences, diagnostic approach and treatment options. J Physiol Pharmacol 2011;62:591-9.

4. Spiller R, Garsed K. Postinfectious irritable bowel syndrome. Gastroenterology 2009;136:1979-88.

5. Rajilic-Stojanovic M, Biagi E, Heilig HG, Kajander K, Kekkonen RA, Tims S, et al. Global and deep molecular analysis of microbiota signatures in fecal samples from patients with irritable bowel syndrome. Gastroenterology 2011;141:1792-801.

6. Saulnier DM, Riehle K, Mistretta TA, Díaz MA, Mandal D, Raza S, et al. Gastrointestinal microbiome signatures of pediatric patients with irritable bowel syndrome. Gastroenterology 2011;141:1782-91.

7. Ford AC, Talley NJ. Mucosal inflammation as a potential etiological factor in irritable bowel syndrome: A systematic review. J Gastroenterol 2011;46:421-31.

8. Schmulson M, Chey WD. Abnormal immune regulation and lowgrade inflammation in IBS: Does one size fit all? Am J Gastroenterol 2012;107:273-5.

9. Collins SM, Bercik P. The relationship between intestinal microbiota and the central nervous system in normal gastrointestinal function and disease. Gastroenterology 2009;136:2003-14.

10. Schmulson M, Pulido-London D, Rodríguez O, Morales-Rochlin N, Martínez-García R, Gutiérrez-Ruiz MC, et al. Lower serum IL-10 is an independent predictor of IBS among volunteers in Mexico. Am J Gastroenterol 2012;107:747-53.

11. Camilleri M. Genetics and irritable bowel syndrome: from genomics to intermediate phenotype and pharmacogenetics. Dig Dis Sci 2009;54:2318-24.

12. Villani AC, Lemire M, Thabane M, Belisle A, Geneau G, Garg AX, et al. Genetic risk factors for post-infectious irritable bowel syndrome following a waterborne outbreak of gastroenteritis. Gastroenterology 2010;138:1502-13.

13. Camilleri M, Katzka DA. Irritable bowel syndrome: Methods, mechanisms, and pathophysiology. Genetic epidemiology and pharmacogenetics in irritable bowel syndrome. Am J Physiol Gastrointest Liver Physiol 2012;302:G1075-84.

14. Smith AJ, Humphries SE. Cytokine and cytokine receptor gene polymorphisms and their functionality. Cytokine Growth Factor Rev 2009;20:43-59.

15. Gonsalkorale WM, Perrey C, Pravica V, Whorwell PJ, Hutchinson IV. Interleukin 10 genotypes in irritable bowel syndrome: Evidence for an inflammatory component? Gut 2003;52:91-3.

16. van der Veek PP, van den Berg M, de Kroon YE, Verspaget HW, Masclee AA. Role of tumor necrosis factor-alpha and interleukin-10 gene polymorphisms in irritable bowel syndrome. Am J Gastroenterol 2005;100:2510-6.

17. Ortiz-Lucas M, Saz-Peiro P, Sebastián-Domingo JJ. Irritable bowel syndrome immune hypothesis. Part two: The role of cytokines. Rev Esp Enferm Dig 2010;102:711-7.
18. Bashashati M, Rezaei N, Bashashati H, Shafieyoun A, Daryani NE, Sharkey KA, et al. Cytokine gene polymorphisms are associated with irritable bowel syndrome: a systematic review and meta-analysis. Neurogastroenterol Motil 2012;24:1102-e566.

19. Schmulson M, Ortiz O, Santiago-Lomeli M, Gutiérrez-Reyes G, Gutiérrez-Ruiz MC, Robles-Díaz G, et al. Frequency of functional bowel disorders among healthy volunteers in Mexico City. Dig Dis 2006;24:342-7.

20. Perrey C, Turner SJ, Pravica V, Howell WM, Hutchinson IV. ARMSPCR methodologies to determine IL-10, TNF-alpha, TNF-beta and TGF-beta 1 gene polymorphisms. Transpl Immunol 1999;7:127-8.

21. Lee HJ, Lee SY, Choi JE, Kim JH, Sung IK, Park HS, et al. G protein beta3 subunit, interleukin-10, and tumor necrosis factor-alpha gene polymorphisms in Koreans with irritable bowel syndrome. Neurogastroenterol Motil 2010;22:758-63.

22. Wang BM, Jiang XZ, Yang YL, Liu WT, Cao XC, Zhao XZ. A study of interleukin-10 gene polymorphism in irritable bowel syndrome. Zhonghua Nei Ke Za Zhi 2006;45:289-92.

23. Santhosh S, Dutta AK, Samuel P, Joseph AJ, Ashok Kumar J, Kurian G. Cytokine gene polymorphisms in irritable bowel syndrome in Indian population - a pilot case control study. Trop Gastroenterol 2010;31:30-3.

24. Liebregts T, Adam B, Bredack C, Röth A, Heinzel S, Lester S, et al Immune activation in patients with irritable bowel syndrome. Gastroenterology 2007;132:913-20.

25. Gecse K, Roka R, Ferrier L, Leveque M, Eutamene H, Cartier C, et al Increased faecal serine protease activity in diarrhoeic IBS patients: a colonic lumenal factor impairing colonic permeability and sensitivity. Gut 2008;57:591-9.

26. Marshall JK, Thabane M, Garg AX, Clark W, Meddings J, Collins SM Intestinal permeability in patients with irritable bowel syndrome after a waterborne outbreak of acute gastroenteritis in Walkerton, Ontario. Aliment Pharmacol Ther 2004;20:1317-22.

27. Dunlop SP, Hebden J, Campbell E, Naesdal J, Olbe L, Perkins AC, et al. Abnormal intestinal permeability in subgroups of diarrhea-predominant irritable bowel syndromes. Am J Gastroenterol 2006;101:1288-94.

28. Chang L, Adeyemo M, Karagiannides I, Videlock EJ, Bowe C, Shih W, et al. Serum and colonic mucosal immune markers in irritable bowel syndrome. Am J Gastroenterol 2012;107:262-72.

29. Barkhordari E, Rezaei N, Ansaripour B, Larki P, Alighardashi M, Ahmadi-Ashtiani HR, et al. Proinflammatory cytokine gene polymorphisms in irritable bowel syndrome. J Clin Immunol 2010;30:74-9.

30. Baran W, Szepietowski JC, Mazur G, Baran E. A-308 promoter polymorphism of tumor necrosis factor alpha gene does not associate with the susceptibility to psoriasis vulgaris. No difference either between psoriasis type I and type II patients. Acta Dermatovenerol Alp Panonica Adriat 2006;15:113-8.

31. Bouma G, Crusius JB, Oudkerk Pool M, Kolkman JJ, von Blomberg $\mathrm{BM}$, Kostense PJ, et al. Secretion of tumour necrosis factor alpha and lymphotoxin alpha in relation to polymorphisms in the TNF genes and HLA-DR alleles. Relevance for inflammatory bowel disease. Scand J Immunol 1996;43:456-63.

32. de Vries N, Tak PP. The response to anti-TNF-alpha treatment: gene regulation at the bedside. Rheumatology (Oxford) 2005;44:705-7.

33. Silva-Zolezzi I, Hidalgo-Miranda A, Estrada-Gil J, Fernández-López JC, Uribe-Figueroa L, Contreras A, et al. Analysis of genomic diversity in Mexican Mestizo populations to develop genomic medicine in Mexico. Proc Natl Acad Sci U S A 2009;106:8611-6.

34. Wang S, Ray N, Rojas W, Parra MV, Bedoya G, Gallo C, et al. Geographic patterns of genome admixture in Latin American Mestizos. PLoS Genet 2008;4:e1000037.

35. Rodríguez-Fandiño O, Hernández-Ruiz J, López-Vidal Y, Charúa L, Bandeh-Moghaddam $\mathrm{H}$, Minzoni A, et al. Intestinal recruiting and activation profiles in peripheral blood mononuclear cells in response to pathogen-associated molecular patterns stimulation in patients with IBS. Neurogastroenterol Motil 2013;25:872-e699. 